\title{
Acceleration of angiogenesis in wound healing after tooth extraction with kirinyuh (Chromolaena odorata) leaf extract
}

\author{
Yosaphat Bayu Rosanto ${ }^{*}$ and Vinka Ardhiyanti ${ }^{2}$ \\ ${ }^{1}$ Departement of Oral and Maxillofacial Surgery, Faculty of Dentistry, Universitas Gadjah Mada, 55282, Yogyakarta, Indonesia \\ ${ }^{2}$ Undergraduate Student of Faculty of Dentistry, Universitas Gadjah Mada, 55282, Yogyakarta, Indonesia
}

\begin{abstract}
Tooth extraction is dental procedure that causes wound in oral cavity. Kirinyuh leaves (Chromolaena odorata) contain flavonoids, saponins and tannins which help the wound healing after tooth extraction. Purpose of study was to determine effect of giving kirinyuh leaf ethanol extract on wound healing after tooth extraction in guinea pigs (Cavia cobaya) in angiogenesis. Sixty male guinea pigs were divided into five groups: aquadest, iodine glycerine (positive control), kirinyuh $2.5 \%, 5 \%$, and $10 \%$. Each group consisted of 12 guinea pigs in each group. Kirinyuh leaf extract was prepared in a topical gel with CMC-Na as the solvent. Left mandibular incisor of guinea pigs was extracted then treated according to the group every day. Guinea pigs were euthanized on days 3, 7, 10, and 14 (three guinea pigs from each group per day) and made histological sections with hematoxylin eosin staining. Angiogenesis was observed with binocular microscope equipped with camera. Results showed that number of new blood vessels in kirinyuh $10 \%$ group reached highest number faster (day 7$)$ than the other groups $(\mathrm{p}=0.000)$. This study concluded that kirinyuh leaves accelerate angiogenesis by increasing the number of blood vessels. The $10 \%$ concentration is the most effective kirinyuh extract concentration to accelerate angiogenesis.
\end{abstract}

\section{Introduction}

Tooth extraction is a dental procedure that causes a wound in the oral cavity in the form of a tooth socket. Healing of tooth sockets is different from healing wounds on the mucosa, bones and skin [1]. Tooth socket healing involves both hard tissue (alveolar bone) as well as soft tissue (gingiva). Saliva in the oral cavity creates a wet wound condition and topical drug is easy to remove. This condition requires topical drug that is able to stick longer and reduce the presence of water in the saliva [2].

Wounds cause loss of tissue continuity that causes the wound area to be deprived of oxygen and nutrients that are essential for healing [3]. Angiogenesis is an important step in the wound healing process because it will overcome the condition [4]. In general, angiogenesis is divided into three phases: initiation, invasion and maturation. The initial factor that triggers the initiation of angiogenesis is tissue damage that causes tissue hypoxia. The hypoxic condition of the tissue becomes an angiogenic stimulator, such as vascular endothelial growth factor (VEGF), which is released from inflammatory cells in the wound area during the previous inflammatory process. These factors stimulate the endothelial invasion of the surrounding blood vessels, causing new blood vessels to sprout. The number of new blood vessels formed is more than the required number. The maturation process will cause selective apoptosis which causes a reduction in the number of new blood vessels to reach the ideal number. Therefore, the angiogenesis process can be assessed by counting the number of blood vessels formed in the wound $[4,5]$.

The kirinyuh (Indonesian) / lahuna (Sundanese) / siam weed (English) / Chromolaena odorata (Latin) is a plant that is so numerous and easy to grow wild everywhere that it is considered a nuisance plant. Kirinyuh thrives and covers open areas such as plantations quickly so that it is classified as a weed crop. The characteristics of this plant are: triangular leaves with three leaf bones that are clearly visible and have a distinctive smell when crushed so that they get the name odorata [6]. Traditionally kirinyuh leaves are used as a wound healing drug [7]. Kirinyuh leaves contain several main compounds, including flavonoids, saponins, tannins, terpenoids and steroids [8]. This study aims to prove that kirinyuh leaves can accelerate wound healing histologically by accelerating the angiogenesis process.

\section{Materials and Methods}

\subsection{Kirinyuh leaf extraction proces}

Kirinyuh leaves were obtained from one of the plantations in Yogyakarta. Plant species and taxonomy were determinate in Plant Systematics Laboratory, Universitas Gadjah Mada. Kirinyuh leaf extraction process begins with washing the kirinyuh leaves that

\footnotetext{
* Corresponding author: yosaphatbr@ugm.ac.id
} 
have been plucked from the stems with water. Leaves thinly sliced and dried in the shade (not exposed to direct sun). The dried kirinyuh leaves are mashed in a blender until they form a powder. The second stage is making $70 \%$ ethanol extract by maceration method. Maceration is the preparation of a liquid preparation by soaking in 5 liters of nonpolar solvent ( $70 \%$ ethanol) for 3 days to extract its natural content. The marinade is filtered with filter paper (Whatman) to obtain the filtrate. The filtrate is evaporated using a vacuum rotary evaporator (Greatwall Scientific Industrial) at $500^{\circ} \mathrm{C}$, so that a green ethanol leaf extract is obtained which will be used as a treatment material for the research subjects. The ethanol extract of kirinyuh leaves was processed into a gel preparation with $\mathrm{CMC}-\mathrm{Na}$ as the solvent. The concentration is made of $2.5 \%, 5 \%$, and $10 \%(\mathrm{w} / \mathrm{w})$..

\subsection{Animal Treatments}

This research was conducted with an ethical eligibility permit 0014 / KKEP / FKG-UGM / EC / 2018 from the Research Ethics Commission of the Faculty of Dentistry, Gadjah Mada University. The guinea pigs were grouped into 5 groups with 12 guinea pigs in each group. The treatment group was given ethanol extract of $2.5 \%, 5 \%$, and $10 \%$ kirinyuh leaves, the positive control group was given glycerin iodine and the negative control group was given distilled water after tooth extraction. Prior to the treatment, all guinea pigs were injected using ketamine $10 \mathrm{mg} / \mathrm{kg}$ intramuscularly on the upper thigh to provide sedation and anesthesia.

The extracted tooth was the mandibular left first incisor. The teeth were luxated with an excavator and then extracted with a hemostat. The dental socket was applied the treatment material according to its group. Application wass carried out with a $0.2 \mathrm{ml}$ injection syringe. The guinea pigs were euthanized by an overdose of diethyl ether sedation on days $3,7,10$, and 14 for 3 guinea pigs from each group.
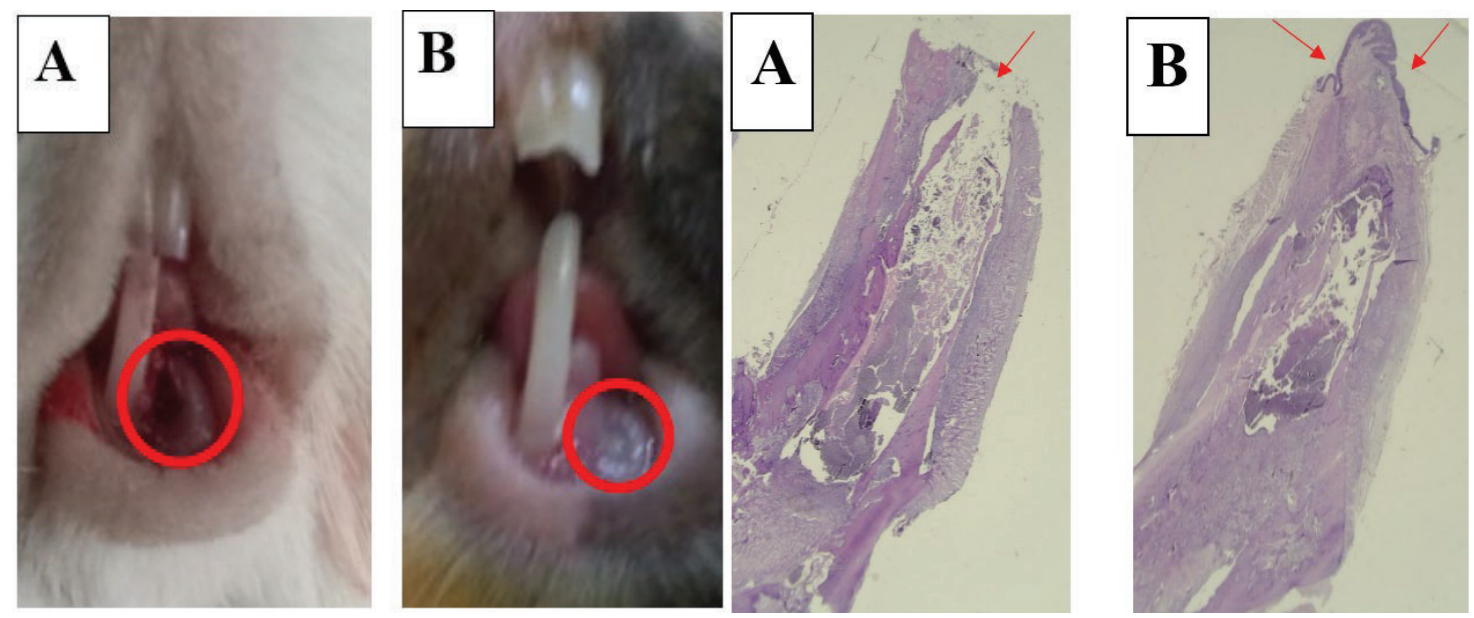

Fig. 1. Clinical and histological features of wound healing in the guinea pig tooth socket immediately after tooth extraction (A) and after the wound was closed on day 14 (B) in the $10 \%$ kirinyuh extract gel group.

\subsection{New Blood Vessel Count (Angiogenesis)}

Observations were carried out by counting the number of blood vessels in the tooth socket in the histological section with hematoxylin eosin (HE) staining under a binocular microscope (Nikon YS 100) attached to a camera (Optilab viewer 2.0) with 100x magnification in 5 fields of view. All observations were made by two observers using blind methods

\subsection{Data Analysis}

The number of blood vessels is a quantitative data ratio. Statistical analysis used SPSS version 26 software (SPSS IBM, New York, USA) with Two-way Anova Test and Post-Hoc Test with Tukey's Test. The confidence level was $95 \%(\mathrm{p}<0.05)$.

\section{Results}

Figure 1 shows clinical gingival wound healing and histologic gingival epithelial formation on HE sections. Histological observation at 40x magnification was used to view the broad area of the tooth socket. Five field of views were choosen in the socket wall from the apex (Figure 2). The dental socket at day 3 was dominated by extravasation of erythrocytes and damaged alveolar bone margins. The dental socket on day 7 showed that erythrocyte extravasation had decreased, inflammatory cells and fibroblasts were more dominant, new blood vessels and intrasocket collagen fibers appeared thin to form granulation tissue. The dental socket on day 10 showed thicker collagen fibers forming granulation tissue, erythrocyte extravasation and inflammatory cells were no longer dominant, and osteoblasts at the edge of the alveolar bone were seen to form an osteoid matrix. The dental socket of day 14 was dominated by trabecular islets with trapped osteocytes and osteoblasts at the edges (Figure 3). 


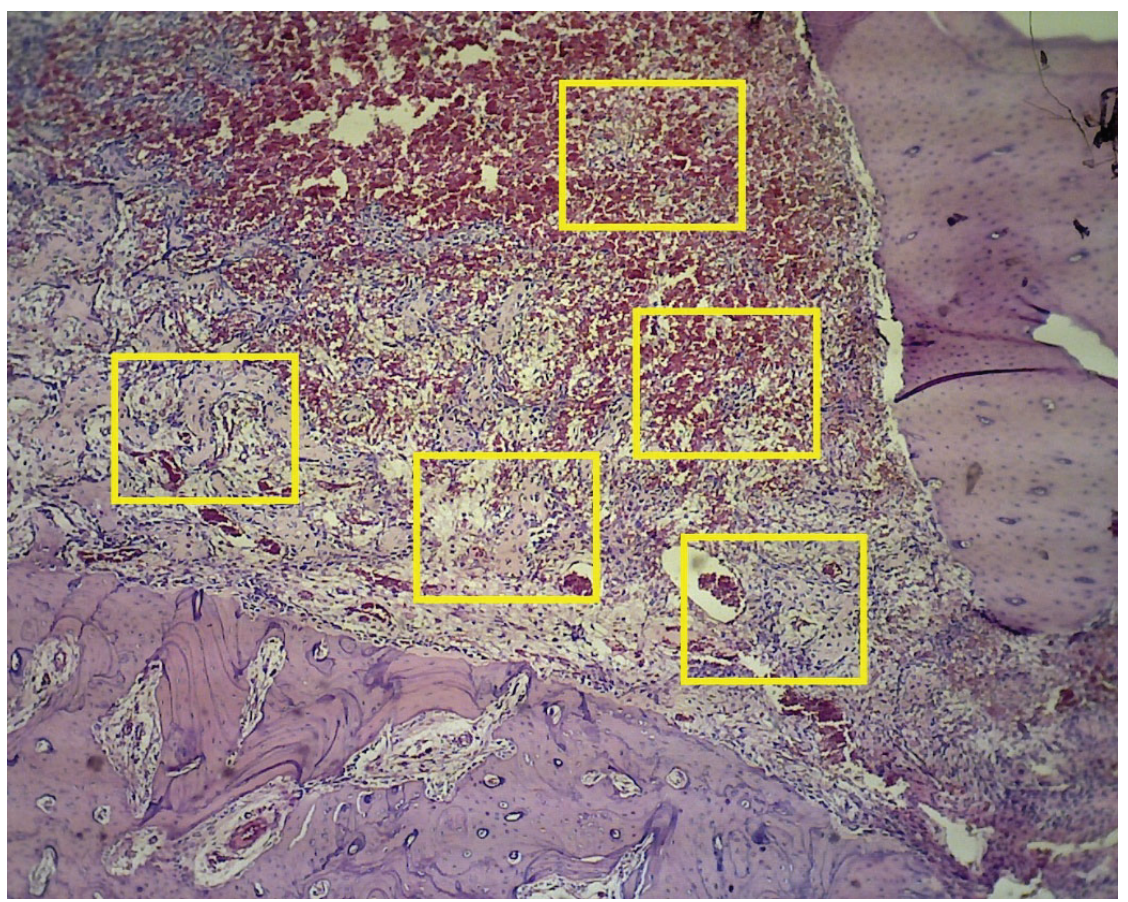

Fig. 2.Histological picture of HE staining of post-extracted tooth sockets in 40x magnification in the $10 \%$ kirinyuh extract treatment group. The yellow box is a field for counting the number of new blood vessels at a magnification of 100x.

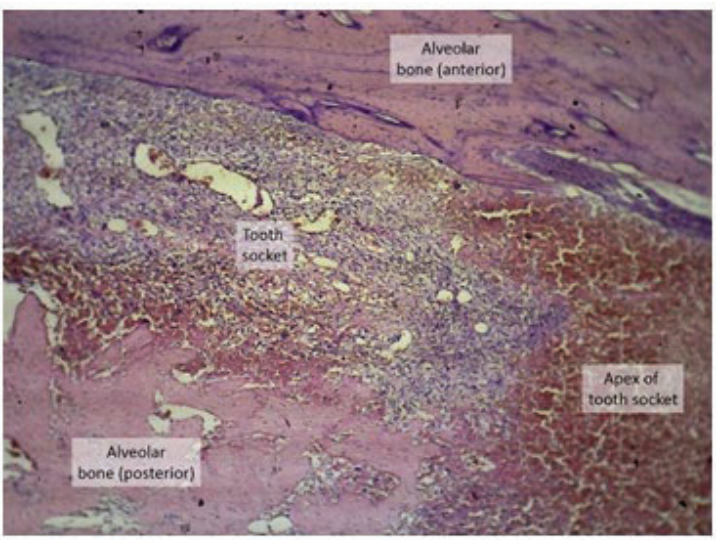

Day 3

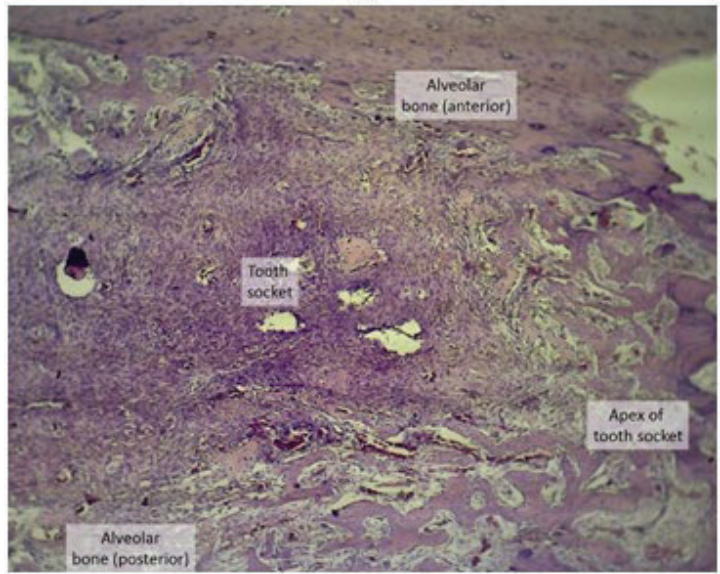

Day-10

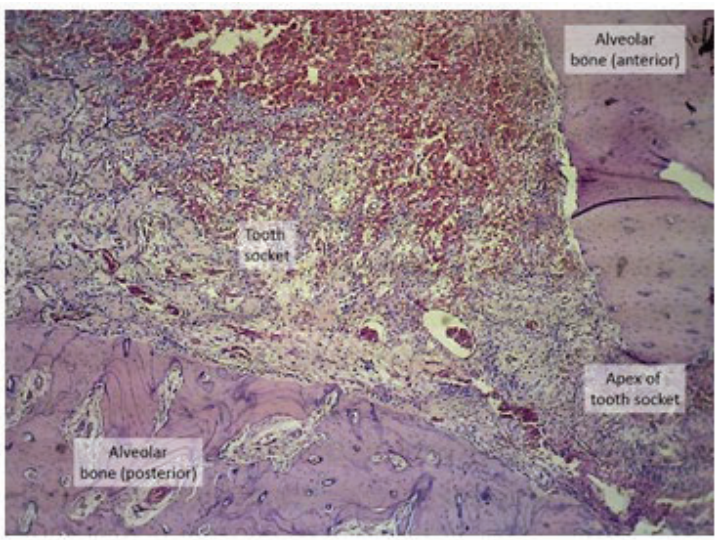

Day 7

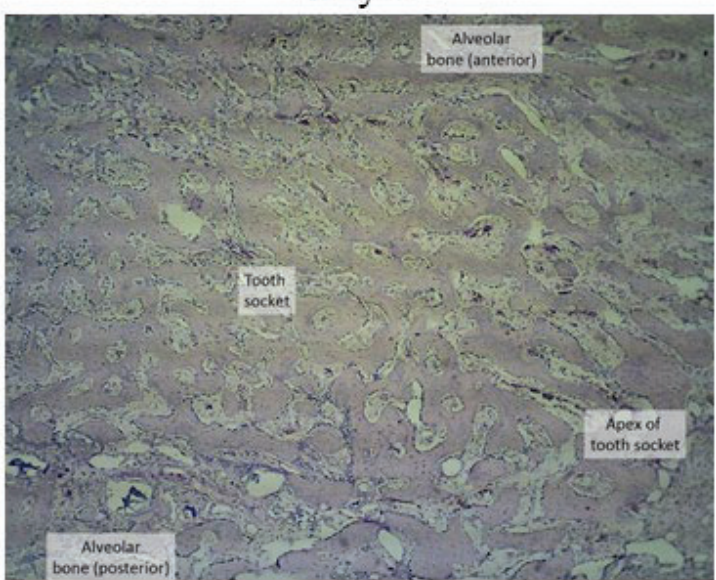

Day-14

Fig. 3. Histological picture of HE staining of tooth sockets on days 3, 7, 10, and 14 after tooth extraction in $40 \mathrm{x}$ magnification in the $10 \%$ left-hand extract treatment group. 
The new blood vessels are counted at $100 x$ magnification which shows a more detailed picture. The vessels in the HE section appear as a lumen filled with blood vessels surrounded by an epithelium with attached endothelial cells (Figure 4). The histological comparison between treatment groups in each day is shown in Figure 5. The angiogenesis calculation results are shown in Figure 6. New blood vessels appeared on day 3 in the group treated with $10 \%$ left leaf extract, while in other groups not yet. All groups showed the presence of new blood vessels on day 7 . New blood vessels in the kirinyuh 10\% group reached their peak on day 7. This number was significantly higher $(p=0.000)$ compared to the other groups and was the highest in the entire study. The number of blood vessels in this group then decreased after the 7th day. This is different from the number of new blood vessels in other groups which still increased after the 7 th day.

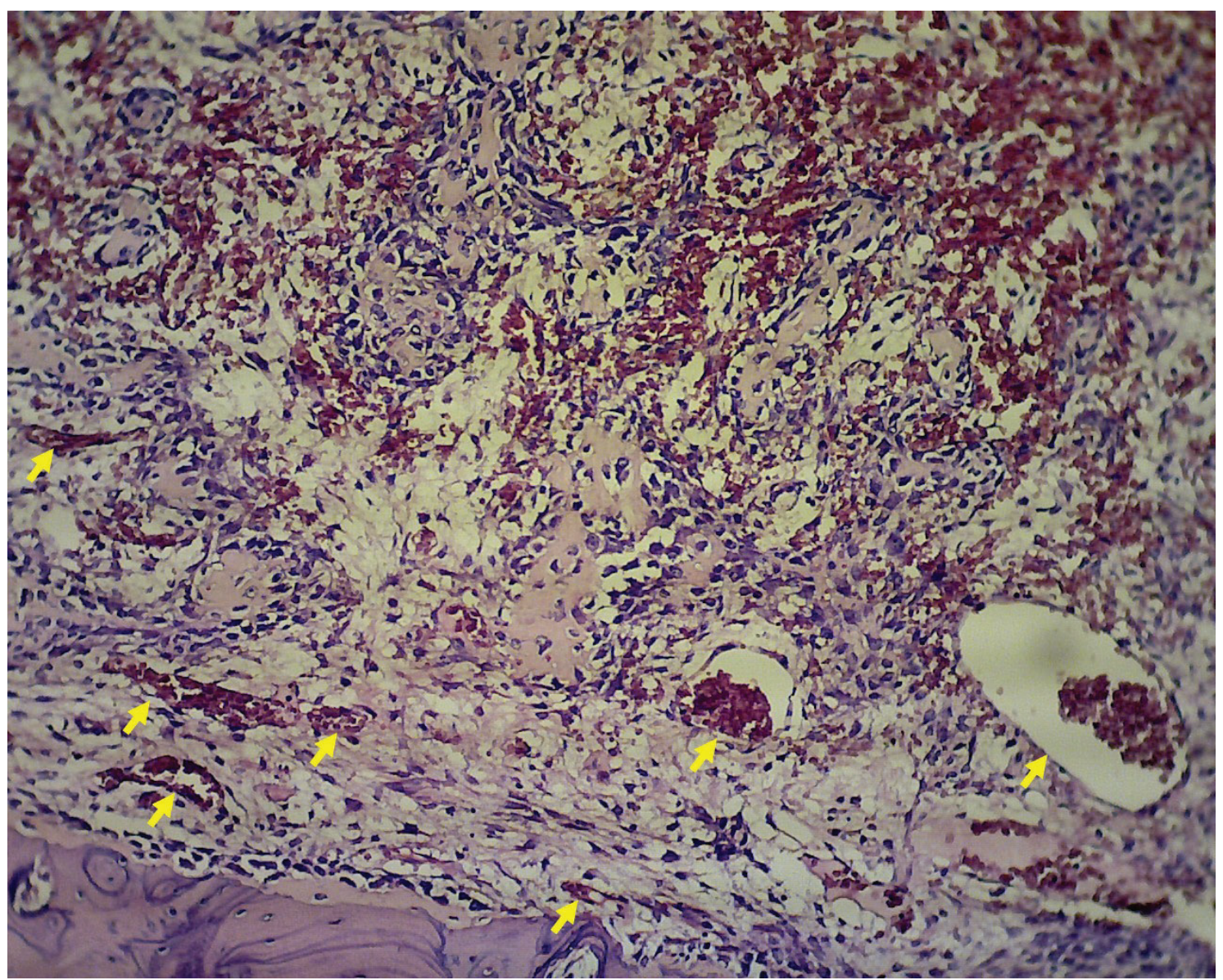

Fig. 4. The blood vessels (yellow arrow) in the HE preparation from kirinyuh $10 \%$ group are shown as a lumen containing blood vessels surrounded by epithelium with endothelial cells attached to the epithel.

The number of blood vessels in glycerin iodine, kirinyuh $2,5 \%$ and $5 \%$ reached the highest number significantly $(\mathrm{p}=0,000)$ on day 10 and all three were reduced on day 14. The new blood vessels in the kirinyuh $5 \%$ group and iodine glycerin had the same amount at day 10 and both were higher than the kirinyuh $2.5 \%$ group. The number of blood vessels in the aquades group continued to increase on the 14th day. This indicates that the angiogenesis process has not yet reached its peak in this group.

\section{Discussion}

Angiogenesis is an important parameter in the wound healing process because it plays a role in maintaining the vitality of damaged tissue due to wounds [9]. The supply of nutrients, such as glucose and amino acids, from systemics is carried through the blood vessels which are formed through the angiogenesis process to optimize the proliferation process and the formation of granulation tissue [10]. Various efforts can be made to optimize angiogenesis in wound healing, such as by stimulating the secretion of VEGF by CD133 + cells, proangiogenic embryo-derived CD133 + progenitor cells, and microfluidic devices, but the use of this biotechnology is less inclusive because it is quite expensive, difficult to obtain, and can only be applied by medical experts [11]. This condition triggers the need for another biotechnological approach, one of which is herbs. 


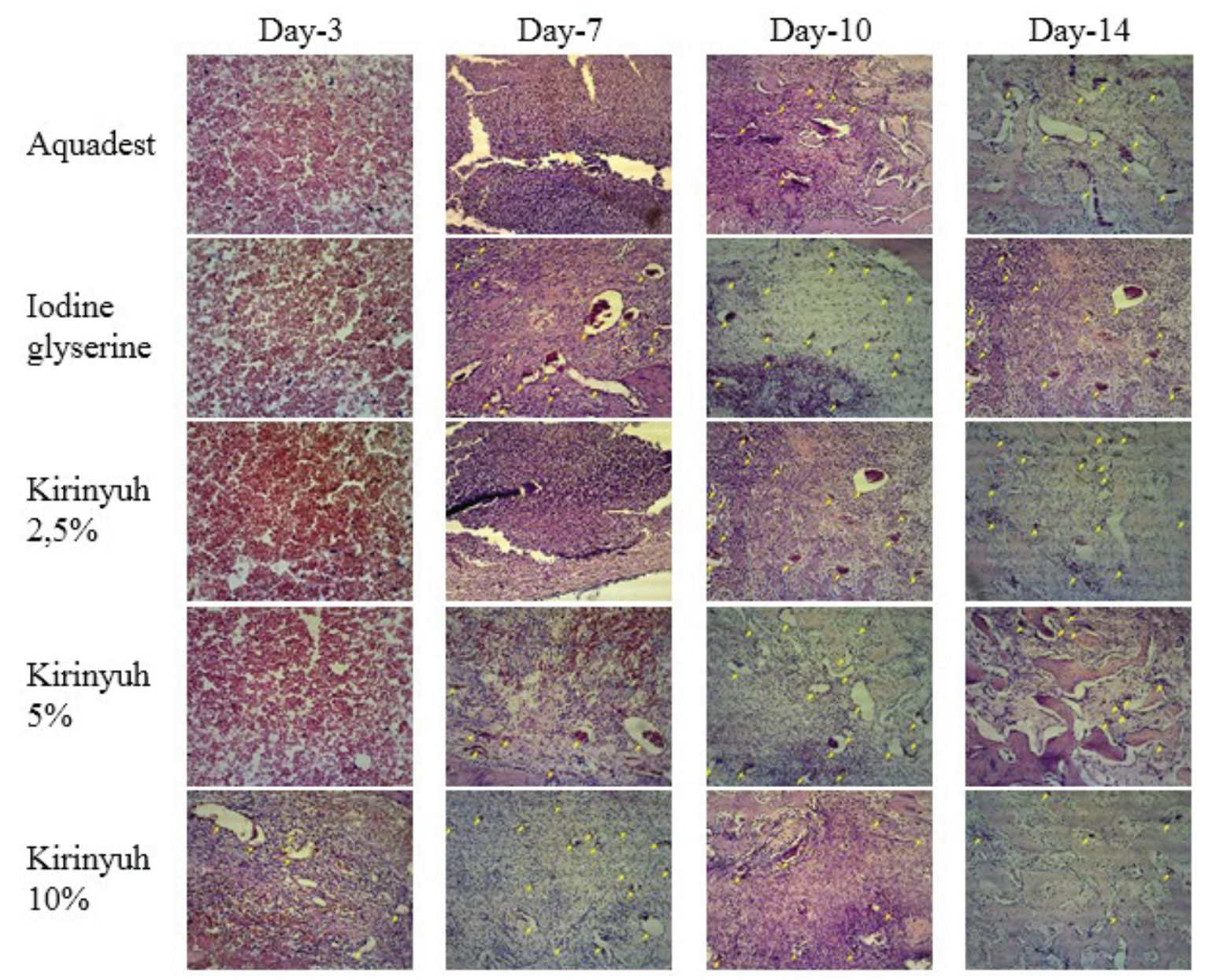

Fig. 5. Count of the number of new blood vessels in each treatment group. New veins are indicated by small yellow arrows.

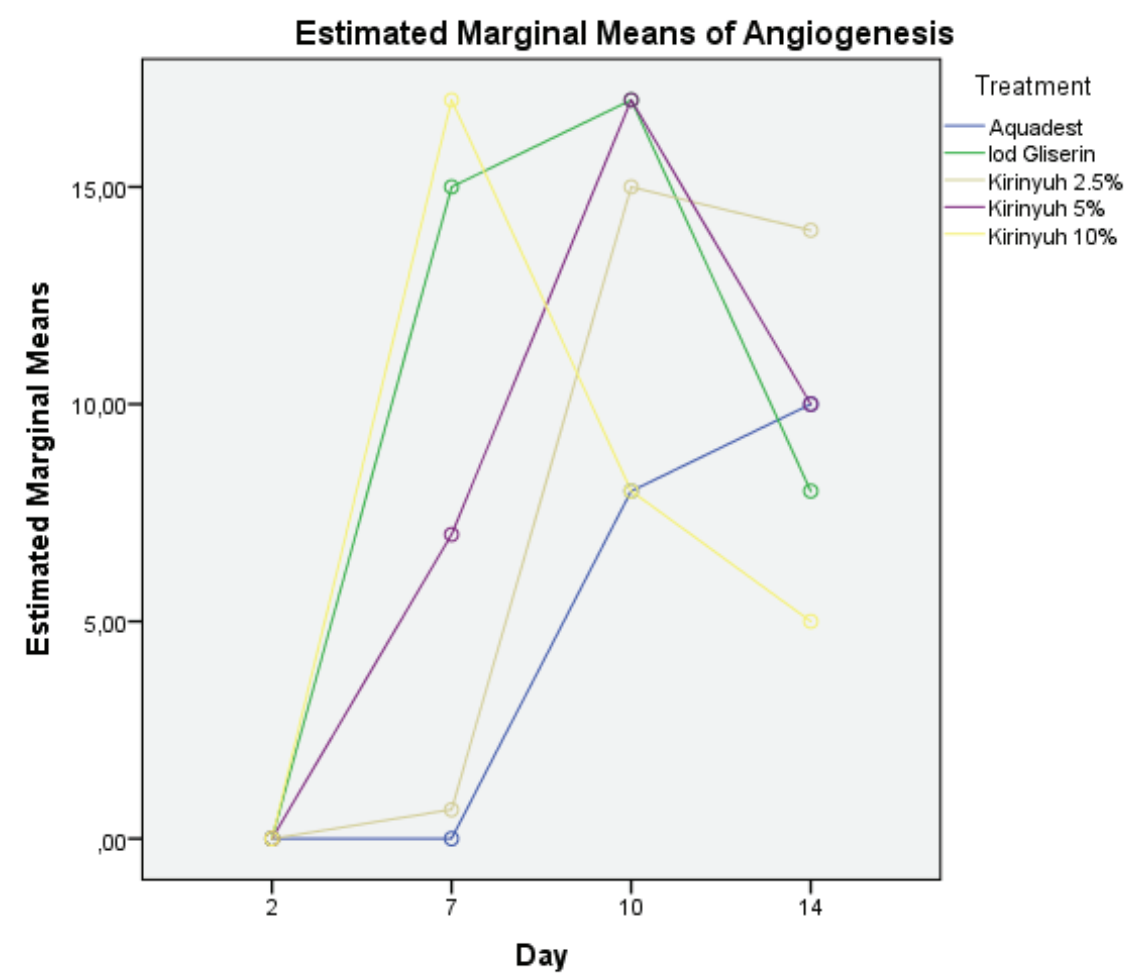

Fig. 6. Graph of average number of new blood vessels from 5 groups on days 3, 7, 10, and 14. 
Various herbs have been studied for their effects on angiogenesis in the wound healing process such as pandan leaves [12], cucumbers [13], pineapple [14], and yellow potatoes [15] due to the content of phenolic compounds such as flavonoids, saponins and tannins.

Application of $10 \%$ kirinyuh leaf extract gel showed the number of blood vessels with a fluctuating pattern in the form of an increase on day 3, peak on day 7, a decrease from day 10 to 14 (Figure 6). This pattern is in accordance with the theory of angiogenesis, an increase followed by a decrease is a mechanism to achieve a balance in the number of blood vessels in the wound healing process [16]. The application of 5\% kirinyuh leaf extract gel and iodine glycerine showed a pattern of fluctuation in the number of new blood vessels with a peak on day 10 and a decrease on day 14 (Figure 6). This shows that the concentration of 5\% kirinyuh leaf extract has the same effect as glycerin iodine, which has been patented as a medicine for wound healing, and the $10 \%$ concentration of kirinyuh leaf extract is proven to be more effective than glycerin iodine. This suggests that kirinyuh leaf extract has the potential to be a patent medicine for wound healing. Angiogenesis that produces more new blood vessels in the wound healing process with kirinyuh leaf extract gel indicates a better optimization of tissue vitality [9]. The content of flavonoids, saponins, and tannins in the $10 \%$ kirinyuh leaf extract gel is thought to be able to stimulate an increase in VEGF and bFGF expression immediately after the wound occurs and during the proliferation phase of wound healing so that it will increase the number of new blood vessels and angiogenesis reaches a peak of proliferation on day 7 .

The process of vascular apoptosis in the treated group with $10 \%$ kirinyuh leaf extract occurred on the 7 th day, also faster than the other groups $(\mathrm{p}=0.000)$. The ingredients in kirinyuh leaves are thought to be able to increase the expression of Ang1, an antiangiogenic factor, which plays a role in decreasing the number of blood vessels on the 7th day, which is the end of the proliferation phase [17]. These results prove that angiogenesis in the wound healing process is best achieved by $10 \%$ kirinyuh leaf extract gel. The process of stabilization and maturation of new blood vessels that is formed is also influenced by the presence of pericite cells in the walls of the blood vessels. A decrease in angiogenesis occurs due to selective apoptotic processes of new blood vessels that do not have pericits $[4,18,19]$. This raises the possibility that the $10 \%$ kirinyuh leaf extract gel also plays a decrease in the end of the proliferation phase on day 7. A longer period of observation is needed to determine the period of stability in the amount of angiogenesis after decreasing.

In addition to the effects of its natural content, the processing of kirinyuh leaves and its formulation in gel form has an effect on angiogenesis. The stability of the content of herbal compounds such as flavonoids, saponins and tannins can be well maintained by processing the extract using the maceration method with ethanol solvent [20]. Kirinyuh 10\% leaf extract gel showed proliferation of angiogenesis occurred until day 7 and maturation occurred on day 10, but in the aquadest group the proliferation occurred until day 14 . The end of the natural proliferation phase marked by a decrease in angiogenesis in day 14 [21]. The conditions on that day had not yet reached optimal wound healing [19].

The location of the wound also affects the angiogenesis process in wound healing. The process of angiogenesis of wounds in the oral cavity is faster than skin wounds [19]. Saliva which always keeps the oral mucosa wet is also a source of VEGF so that it can optimize angiogenesis naturally, especially in the stage of endothelial cell proliferation [22]. However, the condition that is always wet is also an obstacle to the wound healing process which requires moist conditions (not wet). The gel formulation is able to provide a moist condition to the wound tissue so that it can better facilitate VEGF [23]. Angiogenesis in the group treated with kirinyuh leaf extract gel in all groups was faster than the negative control group because of the ability to induce an increase in VEGF expression in endothelial cells during the proliferation phase. More than that, $\mathrm{CMC}-\mathrm{Na}$ as a gelling agent has mucoadhesive properties and supports the diffusion ability of active substances well. CMC-Na can absorb wet conditions in the oral cavity resulting in adequate moisture thus creating a more valley environment to accelerate wound healing, including in the angiogenesis process [24, 25]. Its mucoadhesive properties also make the content of kirinyuh leaves not easily lost by the flow of saliva. Optimization of the physical properties of kirinyuh leaf extract gel is needed to make it more stable in the oral cavity [26].

The specificity of the angiogenesis image is influenced by the histological staining method used [27]. HE staining in this study can identify angiogenesis based on the structure of the lumen, endothelial cells, and erythrocytes. Immunohistochemical (IHC) staining, such as with anti-VEGF monoclonal antibodies, is able to provide an overview of the amount of VEGF expression [29]. Identification of VEGF expression can see the angiogenesis process because of its role as the main proangiogenic factor of wounds [11]. IHC staining is able to identify cellular aspects more specifically to hormonal activity, so that it can further observe the angiogenic effect of kirinyuh leaf extract gel [29].

\section{References}

1. C. Politis, J. Schoenaers, R. Jacobs, J.O. Agbaje, Wound Healing Problems in the Mouth, Front Physiol. 7 (2016) 507. Published online 2016 Nov 2. doi: 10.3389/fphys.2016.00507

2. A. Villa, C.L. Connel, S. Abati, Diagnosis and management of xerostomia and hyposalivation, Ther Clin Risk Manag. 11 (2015) 45-51. Published online 2014 Dec 22. doi: 10.2147/TCRM.S76282 
3. A.M. Szpaderka, C.G. Walsh, M.J. Steinberg, L.A. DiPietro, Distinct Patterns of Angiogenesis in Oral and Skin Wound, J Dent Res. 84(4) (2005) 309-314.

4. Y.B. Rosanto, C.Y. Hasan, R. Rahardjo, T.W. Pangestiningsih, Effect of snail mucus on angiogenesis during wound healing, F1000 Research. 10 (2021) 181.

5. D.R. Senger, G.E. Davis. Angiogenesis. Cold Spring Harb Perspect Biol. 3(8) (2011) a005090. doi: 10.1101/cshperspect.a005090.

6. A. Sirinthipaporn, W. Jiraungkoorskul, Wound Healing Property Review of Siam Weed, Chromolaena odorata, Pharmacogn Rev. 11(21) (2017) 35-38. doi: 10.4103/phrev.phrev_53_16

7. A. Shedoeva, D. Leavesley, Z. Upton, C. Fan. Wound Healing and the Use of Medicinal Plants, Hindawi. Evidence-Based Complementary and Alternative Medicine. Article ID 2684108 (2019) 30 pages. https://doi.org/10.1155/2019/2684108

8. A.C. Akinmoladun, E. Ibukun, I.A.D. Dan-Ologe, Phytochemical constituents and antioxidant properties of extracts from the leaves of Chromolaena odorata, Scientific Research and Essays 2(6) (2007) 191-194

9. K.E. Johnson, T.A. Wilgus, Vascular Endothelial Growth Factor and Angiogenesis in the Regulation of Cutaneous Wound Repair, Adv Wound Care (New Rochelle). 3(10) (2014) 647-661. doi: 10.1089/wound.2013.0517

10. M.B. Serra, W.A. Barroso, N.N. da Silva, S.N. Silva, A.C.R. Borges, I.C. Abreu, M.O.D. Borges, From Inflammation to Current and Alternative Therapies Involved in Wound Healing, Int J Inflam. 3406215 (2017). doi: 10.1155/2017/3406215.

11. T.N. Demidova-Rice, J.T. Durham, I.M. Herman, Wound Healing Angiogenesis: Innovations and Challenges in Acute and Chronic Wound Healing, Advances in Wound Care, 1(1) (2012) 17-22.

12. G.G. Raj, H.S. Varghese, S. Kotagiri, B.M.V. Swamy, A. Swamy, R.K. Pathan, Anticancer Studies of Aqueous Extract of Roots and Leaves of Pandanus Odoratissimus f. ferreus (Y. Kimura) Hatus: An In Vitro Approach, J Tradit Complement Med. 4(4) (2014) 279-284. doi: 10.4103/22254110.129199

13. T.L. Wargasetia, Widodo, Mechanisms of cancer cell killing by sea cucumber-derived compounds, Invest New Drugs. 35(6) (2017) 820-826. Published online 2017 Sep 18. doi: 10.1007/s10637-017-0505-5

14. V. Rathnnavelu, N.B. Alitheen, S. Sohila, S. Kanagesan, R. Ramesh, Potential role of bromelain in clinical and therapeutic applications. Biomed Rep. 5(3) (2016) 283-288. Published online 2016 Jul 18. doi: 10.3892/br.2016.720

15. G.P. Rosas-Cruz, C.R. Silva-Correa, A.A. Calderon-Pena, V.E.V. Tore, C.L. Aspajo-Villalaz, J.L. Cruzado-Razco, J. del Rosario-Chavarri, J. Rodriguez-Soto, O.E. Pretel-Sevillano, W.A. Sagastegui-Guarniz, A.D. Gonzales-Siccha,
Wound Healing Activity of an Ointment from Solanum tuberosum L. "Tumbay Yellow Potato" on Mus musculus Balb/c, Pharmacognosy Journal 12(6) (2020) DOI:10.5530/pj.2020.12.175

16. H. Larjava, Oral Wound Healing Cell Biology and Clinical Management, first ed., Wiley-Balckwell, Oxford, 2012. pp.125-134,175-181.

17. T.M. Honnegowda, P. Kumar, E. Govindarama, P. Udupa, S. Kumar, U. Kumar, P. Rao, Role of angiogenesis and angiogenic factors in acute and chronic wound healing, Plast Aesthet Res 2: (2015) 243-249. doi: 10.4103/2347-9264.165438

18. P. Bao, A. Kodra, M. Tomic-Canic, M.S. Golinko, H.P. Ehrlich, H. Brem, The Role of Vascular Endothelial Growth Factor in Wound Healing, Journal of Surgical Research. 153(2) (2009) 347358.

19. L.A. DiPietro, Angiogenesis and wound repair: when enough is enough, Journal of Leukocyte Biology, 100(5) (2016) 979-984.

20. Q.W. Zhang, L.G. Lin, W.C. Ye, Techniques for extraction and isolation of natural products: a comprehensive review, Chin Med. 13 (2018) 20. Published online 2018 Apr 17. doi: 10.1186/s13020-018-0177-x

21. A.C.O. Gonzalez, T.F. Costa, Z.A. Andrade, A.R.A.P. Medrado. Wound healing - A literature review, An Bras Dermatol 91(5) (2016) 614-620. doi: 10.1590/abd1806-4841.20164741

22. T. Upile, W. Jerjes, P. Kafas, S. Harini, S.U. Singh, M. Guyer, M. Bentley, H. Sudhoff, C. Hopper, Salivary VEGF: a non-invasive angiogenic and lymphangiogenic proxy in head and neck cancer prognostication, International archives of medicine. 2(1) (2009) 1-12.

23. P.G. Bowler, B.I. Duerden, D.G. Armstrong. Wound Microbiology and Associated Approaches to Wound Management, Clin Microbiol Rev. 14(2) (2001) 244-269. doi: 10.1128/CMR.14.2.244269.2001

24. S. Gibbs, S. Roffel, M. Meyer, A. Gasser, Biology of Soft Tissue Repair: Gingival Epithelium in Wound Healing and Attachment to the Tooth and Abutment Surface, European Cells and Materials. 38 (2019) 63-78.

25. L.A. Sarpe, A.M. Daily, S.D. Horava, N.A. Peppas, Therapeutic applications of hydrogels in oral drug delivery, Expert Opin Drug Deliv. 11(6) (2014) 901-915.

26. A.Q. Bhuiyan, M.S. Rahman, Improvement of Swelling Behaviour of Poly (Vinyl Pyrrolidone) and Acrylic Acid Blend Hydrogel Prepared By the Application of Gamma Radiation, Organic Chemistry: Current Research. 4(2) (2015) 1-8.

27. M. Sprindzuk, A. Dmitruk, V. Kovalev, A. Bogush, A. Tuzikov, V. Liakhovski, M. Fridman, Computer-aided Image Processing of Angiogenic Histological, J Clin Med Res. 1(5) (2009) 249-261. 
Published online 2009 Dec 28. doi: 10.4021/jocmr2009.12.1274.

28. van der Loos, L.B. Meijer-Jorna, M.E.C. Broekmans, H.P.H.M. Ploegmakers, P. Teeling, O,J de Boer, A.C. van der Wal, Anti-human Vascular Endothelial Growth Factor (VEGF) Antibody Selection for Immunohistochemical Staining of Proliferating Blood Vessels, J Histochem Cytochem. 58(2) (2010) 109-118. doi: 10.1369/jhc.2009.954586

29. S.K. Suvarna, C. Layton, J.D. Bancroft, Bancroft's Theory and Practice of Histological Techniques Human Pathology, eigth ed. Elsevier, New York, 2019. pp. 114,126-137. 